\title{
MILITARES REPUBLICANOS EN LA RESTAURACIÓN: DE LA REBELIÓN \\ AL EXILIO (1883-1891)
}

\author{
EdUARdo Higueras CASTAÑEda \\ UNIVERSIDAD DE CASTILLA-LA MANCHA
}

RESUMEN: El artículo analiza las estrategias de supervivencia y estructuras organizativas de la emigración republicana española procedente de las rebeliones de 1883 y 1886. El exilio significó una ruptura vital que implicaba una transformación tanto en los modos de vida como en los marcos mentales de quiénes lo padecieron. Por ello se prioriza el análisis de la experiencia de los emigrados a través de sus propios testimonios, utilizando para ello abundante documentación inédita.

PALABRAS CLAVE: España, exilio, republicanismo, Restauración, Ruiz Zorrilla, ejército.

\section{MILITARY REPUBLICANS UNDER MONARCHICAL RESTORATION: FROM REBELLION TO EXILE (1883-1891)}

\begin{abstract}
This work analyzes the survival strategies and organizational structures of the Spanish Republican exiles from the 1883 and 1886 rebellions. Exile meant a vital break for those who endured it, both in their lifestyle and in their mental frameworks. Therefore, the analysis of the political emigrants' experience through their own testimonies has been prioritized by making use of abundant unpublished documentation.
\end{abstract}

KEY WORDS: Spain, exile, republicanism, monarchical restoration, Ruiz Zorrilla, army.

Recibido: 28-06-2103/Aceptado: 03-09-2013

\footnotetext{
${ }^{1}$ Este trabajo se enmarca en el programa FPU del MEC (AP2009-2610), y del proyecto financiado por el MCINN: El republicanismo radical: anclajes sociológicos y significaciones populistas, 1854-1895 (HAR2010-16962). Asimismo, debo agradecer la atenta colaboración de los responsables de la Fundación Esquerdo y de su Archivo Histórico.
} 


\section{INTRODUCCIÓN}

La Restauración se construyó sobre la marginación de las opciones políticas incompatibles con la monarquía de Alfonso XII. Esa exclusión política se tradujo, a menudo, en expatriación forzosa. El episodio más conocido y, quizás, más representativo de ello fue la orden de expulsión decretada contra Manuel Ruiz Zorrilla por el gobierno de Cánovas en $1875^{2}$. El líder progresista pretendía contrarrestar el golpe de Sagunto recurriendo a la fuerza militar. Pero el destierro no fue siempre una medida excepcional o reservada para casos extremos. En noviembre del mismo año, por ejemplo, el embajador británico informaba que tres ex diputados fueron expatriados for having put their hats on in the stalls at the opera House between the acts when His majesty was present?

En este nuevo contexto político un sector del republicanismo optó por oponerse frontalmente al régimen monárquico. Ruiz Zorrilla fue su cabeza más visible y activa. Por ello, es imprescindible analizar su comportamiento y sus actividades para evaluar el alcance de la oposición violenta a la Restauración ${ }^{4}$. En la opción republicana revolucionaria que lideraba, el ejército ocupó un lugar central como palanca de cambio político. La preferencia por la vía insurreccional frente a la legal llevó a un persistente esfuerzo para la captación de oficiales y suboficiales republicanos o, simplemente, descontentos con su situación profesional. Pero los militares no fueron simples comparsas del líder progresista: en torno a 1881 surgieron diferentes agrupaciones secretas que buscaron el amparo de partidos o personalidades políticas de relieve. Algunas de ellas se fundieron en la Asociación Republicana Militar (ARM), protagonista de la sublevación de agosto de $1883^{5}$. Tras el fracaso de esta rebelión, la ARM se reorganizó como Asociación Revolucionaria Militar, conciliándose con otra agrupación clandestina preexistente, de orientación republicana

\footnotetext{
2 Vid. MARTÍNEZ DE SAS, María Teresa: "Los últimos años de un conspirador. El insurreccionalismo zorrillista durante la restauración (1875-1895)", Boletín de la Real Academia de la Historia, 201 (2004), pp. 425457 y MARTÍNEZ LÓPEZ, Fernando: "La corte revolucionaria. Ruiz Zorrilla en París", en F. Martínez, J. Canal y E. Lemus (Eds.): París, ciudad de acogida. El exilio español durante los siglos XIX y XX, Madrid, Marcial Pons, 2010, pp. 113-157.

${ }^{3}$ Embajada británica en España al Foreign Office (26-11-1875), en Public Record Office, Foreign Office [PRO/FO], 72/1213.

${ }^{4}$ GONZÁLEZ CALLEJA, Eduardo: La razón de la fuerza. Orden público, subversión y violencia política en la España de la Restauración (1875-1917), Madrid, CSIC, 1998, p. 77.

5 Vid. Miguel Pérez y Antonio C. de Arias a Ruiz Zorrilla (22-12-1881), en Archivo Histórico Fundación Esquerdo, Archivo Manuel Ruiz Zorrilla [AHFE/AMRZ], Exilio 9, C 113 y Moncada a Ruiz Zorrilla, (15-41882), en AHFE/AMRZ, Exilio 9, C 114. La principal fuente sobre la ARM es el folleto de SIFFLER-725 [Seud. Miguel Pérez]: Don Manuel Ruiz Zorrilla ante la A.R.M., Madrid, Imprenta de José de Rojas, 1883. Es una obra intencionadamente imprecisa, en la que se basa, entre otros trabajos, el de BUSQUETS, Julio: "La Asociación Republicana Militar", Historia 16, no 128 (1986), pp. 20-28.
} 
federal ${ }^{6}$. Esta nueva ARM sirvió de base para las distintas tentativas revolucionarias hasta, al menos, 1891. Sin embargo, el pronunciamiento del general Villacampa, en septiembre de 1886, fue su última demostración significativa de actividad.

En la medida en que Ruiz Zorrilla fue el eje de las principales rebeliones de este periodo, también lo fue de la emigración ${ }^{7}$ provocada por ellas. El líder progresista condicionó su regreso a España al de los exiliados que él mismo había comprometido. Por ello se convirtió en el organizador del exilio republicano español en Francia, Argelia, Bélgica, Inglaterra, Suiza e incluso Iberoamérica. Tras la serie de indultos y amnistías que beneficiaron a los refugiados carlistas y cantonales, la emigración republicana zorrillista constituyó el principal contingente del exilio español entre 1880 y $1895^{\circ}$. Sus perfiles frente a otros refugiados eran nítidos: en su mayoría eran militares y generalmente ajustaron su comportamiento a lo que el partido revolucionario les exigía. Esa sumisión fue posible, sobre todo, por su dependencia económica respecto al mismo. La tendencia a convivir con los compañeros como condición para la supervivencia facilitó el desarrollo de un sentimiento de identidad, reforzado por la creación de estructuras de encuadramiento, con facultades incluso disciplinarias.

\section{LA EMIGRACIÓN REPUBLICANA DE 1883}

El fracaso del movimiento revolucionario de 1883 produjo la mayor de las emigraciones causadas por las conspiraciones zorrillistas. Sus organizadores habían previsto la sublevación simultánea de 22 guarniciones para la noche del cuatro de agosto ${ }^{10}$. En el último momento esta fecha se retrasó. La contraorden, sin embargo, fue malinterpretada por la Junta de Badajoz, que determinó actuar conforme al plan previsto. El día cinco la ciudad estaba controlada por los rebeldes. Se proclamó la República. Horas más tarde, al comprobar que el movimiento estaba aislado, los sublevados decidieron retirarse hacia la frontera de Portugal ${ }^{11}$. Cuando el coronel Asensio Vega, jefe militar de la insurrección,

\footnotetext{
${ }^{6}$ Carta de Siffler y el T. de Madrid a Ruiz Zorrilla, (5-2-1882), en AHFE/AMRZ, Exilio 9, C 113. Escribe sobre esta asociación MUÑOZ EPELDE, Melchor: Memorias de un amnistiado, Badajoz, 1903, pp. 27 y 173.

${ }^{7}$ Utilizo dicho término en su sentido de exilio o destierro, y, al mismo tiempo, para aludir al conjunto de los emigrados. Vid. FUENTES, Juan Francisco: “Emigración” en J. Fernández Sebastián y J. F. Fuentes (Dirs.): Diccionario político y social del siglo XIX español, Madrid, Alianza Editorial, 2002, p. 268.

8 VILAR, Juan B.: La España del Exilio. Las emigraciones políticas españolas en los siglos XIX y XX, Madrid, Síntesis, 2006, p. 302.

9 GONZÁLEZ CALLEJA, Eduardo: "Republicanos", en J. Canal (Ed.): Exilios. Los éxodos políticos en la historia de España. Siglos XV-XX, Madrid, Sílex, 2007, p. 192.

${ }^{10}$ Las guarniciones comprometidas se citan en la memoria enviada por Serafín Asensio Vega a Manuel Ruiz Zorrilla, AHFE/AMRZ, Exilio 43, L 9.

${ }^{11}$ Sobre el movimiento de Badajoz, Vid. MUÑOZ EPELDE, Melchor: op. cit., pp. 37-94.
} 
ordenó la incautación de los fondos de los batallones y de la Tesorería Provincial, su propósito de prevenir las dificultades del exilio era evidente ${ }^{12}$. La alternativa era resistir a las tropas enviadas por el gobierno, pero el riesgo de un bombardeo aconsejaba la huída. Gran parte de los comprometidos tenían familia y propiedades en la ciudad ${ }^{13}$.

Ante la evidencia del fracaso, la perspectiva de huir al país vecino era un mal menor. Portugal había servido de refugio para los militares y civiles rebeldes en otras ocasiones. El sedimento formado por esa emigración facilitó la integración de los exiliados republicanos en los primeros años de la Restauración ${ }^{14}$. Además, la proximidad de Badajoz permitía mantener el contacto con la familia. 95 jefes y oficiales, 54 sargentos, 725 cabos y soldados y 50 civiles abandonaron la ciudad. Acamparon, a la espera de noticias, junto a la frontera ${ }^{15}$. El temor a que en Portugal les fueran requisados los fondos sustraídos justificó la entrega de dos sueldos para los militares y una cantidad equivalente para los civiles: 10 duros a cada soldado, 12 a los cabos segundos, 14 a los sargentos segundos y 16 a los primeros, así como dos pagas a los oficiales y jefes con arreglo a los dos empleos que la Junta revolucionaria les concedía ${ }^{16}$.

Rubén Landa, jefe civil del movimiento y Ezequiel Sánchez, comisionado de la ARM en Badajoz, fueron los encargados de la gestión de los fondos. La desorganización fue absoluta y los conflictos comenzaron inmediatamente. Landa afirmaba que el dinero no había sido contado al abandonar la plaza por falta de tiempo. Sin embargo, al gobierno español le constaba que esa cantidad ascendía a 345.820 ptas., tal y como figuraba en un acta firmada por el anterior ${ }^{17}$. Posteriormente se le acusó de haber distribuido discrecionalmente dinero, incluyendo a sus familiares en el reparto ${ }^{18}$. Según Ezequiel Sánchez aquello era un diluvio de ladrones ${ }^{19}$. A las cinco de la tarde del día seis cruzaron la frontera. Las tropas portuguesas los custodiaron hasta Elvas, donde se hicieron nuevos repartos de socorros.

Al día siguiente numerosos familiares llegaron en tren desde Badajoz. Los testimonios de ese encuentro y de la despedida ilustran crudamente la quiebra vital y el derrumbe moral que conlleva el exilio. Los emigrados rompían bruscamente con su

12 Vid. SÁNCHEZ, Ezequiel: "Sublevación de Badajoz y distribución de fondos", (Orán, 17-11-1883), en AHFE/AMRZ, Exilio 8, C 73.

${ }^{13}$ EXPÓSITO, Adolfo: "Apuntes de los sucesos acaecidos durante la emigración. Da principio en el día 5 de Agosto de 1883”, en AMAE, H 2868.

${ }^{14}$ Así lo atestiguan ESTÉVANEZ MURPHY, Nicolás: Fragmentos de mis memorias, Madrid, Hijos de R. Álvarez, 1903, p. 468-169 y 471-474; y RODRÍGUEZ SOLÍS, Enrique: Memorias de un revolucionario, Madrid, Editorial Plutarco, 1931, pp. 244-257.

${ }^{15}$ MUÑOZ EPELDE, Melchor: op. cit. p. 98.

${ }^{16}$ SÁNCHEZ, Ezequiel: op. cit.

17 Vicecónsul de España en Elvas al Ministro de Estado, (14-8-1883), Archivo del Ministerio de Asuntos Exteriores de España [AMAE], H 2868.

18 "Contienda entre los señores Vega y Landa", AHFE/AMRZ, Exilio 43, C 11, hojas 9-14.

${ }^{19}$ SÁNCHEZ, Ezequiel: op. cit. 
entorno cotidiano, con sus expectativas, con su profesión, dejando a sus familias en una situación sumamente precaria. El capitán Adolfo Expósito, dirigiéndose a sus hijos, escribió:

Llega el tren correo del día 9 y desembarcan infinitas familias, se estrechan entre sus brazos y permanecen cual letargo en esta situación [...] amanece el día siguiente después de una noche horrible con su buena fiebre, y en el tren de la mañana llegan otra porción de familias y amigos, sucede lo propio que el día anterior; llega la noche [...] todos lloran a sus hijos, a sus mujeres ${ }^{20}$.

Expósito tenía mujer y cuatro hijos. Esperaba uno más. No pertenecía a la ARM. Se había sumado al movimiento por creerlo triunfante, ya que Badajoz siembre había sido una plaza adherente, nunca iniciante ${ }^{21}$. Entre los militares que habían organizado el movimiento y aquéllos que lo habían secundado se había abierto una brecha evidente. Los segundos culpaban a los miembros de la ARM de su situación, pero al mismo tiempo dependían de ellos. De entrada, porque el gobierno portugués les había reconocido de hecho como interlocutores para decidir por los demás. En segundo lugar, porque disponían de los fondos de la Tesorería Provincial.

La presencia en territorio portugués de un millar de refugiados constituía un problema evidente para las autoridades de ambos países. El gobierno español pretendía que no se les reconociera el estatuto de emigrados políticos, de modo que pudieran ser extraditados. El gobierno portugués, sin embargo consideraba que los autores de una insurrección no podían ser considerados delincuentes comunes: el baberse apoderado de los caudales públicos es una medida de guerra que [...] no entra en el número de los delitos que dan lugar a la extradición ${ }^{22}$. Reconocía, por otra parte, que Portugal carecía de profundidad geográfica para mantener alejados de España a los emigrados ${ }^{23}$. Al mismo tiempo, temía que éstos fueran tan peligrosos para las instituciones y el orden en Portugal como para España ${ }^{24}$.

Por ello, se decidió deportar a los oficiales y civiles, haciéndoles optar entre cuatro posibles destinos: Cabo Verde, las Azores, Francia o Inglaterra. De momento sólo veintiún emigrados, entre ellos los máximos dirigentes del movimiento, habían sido trasladados a

\footnotetext{
${ }^{20}$ Vid. EXPÓSITO, Adolfo: "Sucesos políticos acaecidos en la plaza de Badajoz en la noche del 4 al 5 de Agosto y su transcurso en la emigración", en AMAE, H 2868.

${ }^{21}$ Ibidem.

${ }^{22}$ El Encargado de negocios interinos de la Legación de España en Lisboa al Ministro de Estado (7-8-1883), AMAE, H 2868, $\mathrm{n}^{\circ} 118$.

${ }^{23}$ Embajador de S. M. en Lisboa al Ministro de Estado (Lisboa, 26-10-1876), AMAE, H 2632, nº 314.

${ }^{24}$ Ministro de Estado al Embajador de S. M. en Lisboa [A. de Castro], (29-10-1876), AMAE, H 2632. Sobre las conexiones entre los republicanos españoles y portugueses, Vid. Despacho del Embajador de S. M. en Lisboa al Ministro de Estado, (1-1-1877), AMAE, H 2632, nº 368.
} 
Lisboa. La mayoría optaron por Francia ${ }^{25}$ y comunicaron su decisión a los restantes. La expectativa de permanecer cerca de la frontera quedó frustrada. Sin embargo, aquellos militares que no habían participado en la organización del movimiento intentaron elevar una solicitud al gobierno luso para que les autorizase a residir en Portugal. La firmaban 31 individuos. Cuando se apercibieron los Jefes, comenzaron a sembrar la cizaña entre todos, a fin de que dicha relación no adquiriera gran numero de firmantes ${ }^{26}$. Para los jefes de la insurrección era importante la unidad de acción de toda la emigración. Asensio Vega logró que retiraran la solicitud.

Durante algunos días permanecieron confinados en un vapor inservible desde donde protestaron, esta vez en bloque, por la expulsión del territorio portugués ${ }^{27}$. Al fin, fueron trasladados en un transporte de guerra al norte de Francia ${ }^{28}$. Desembarcaron en Cherbourg, el punto más distante de la frontera española, con destino a Rennes, donde se les internó el día $22^{29}$. Llevar a un emigrado -escribía el periodista republicano Rodríguez Solís- lejos de la frontera de su país, en la cual puede encontrar medios de subsistencia, visitas de parientes o amigos, amparo y protección, es sentenciarlo a una verdadera agonía, a un peligro de muerte ${ }^{30}$. Esta era la situación en la que quedaban la mayor parte de los exiliados de Badajoz. En pocos días, se les unió un nuevo grupo de emigrados, procedentes de Cataluña.

La anticipación de la guarnición de Badajoz tuvo el doble efecto de prevenir al gobierno e inhibir a las restantes plazas comprometidas. Aún así, los días 8 y 9 de agosto estallaron dos nuevos focos rebeldes en Santo Domingo de la Calzada y la Seo de Urgel. Ninguno de los militares implicados en el primero de los puntos pudo escapar. El teniente Cebrián murió a manos de un soldado. Cuatro sargentos fueron fusilados ${ }^{31}$. La proximidad de la frontera, en cambio, favoreció a los rebeldes de la Seo de Urgell. El 10 llegaron a Andorra. Un día más tarde regresaron a España algunos cabos y soldados, a la espera de obtener el indulto. Los

\footnotetext{
25 MUÑOZ EPELDE, Melchor: op. cit. p. 106 y RUBIO BÁEZ, Daniel: Memoria del movimiento de Badajoz, (Montauban, 10-4-1885), en AHFE/AMRZ: Exilio 43, L 20.

${ }^{26}$ EXPÓSITO, Adolfo: op. cit.

27 Vid. las cartas dirigidas por los representantes de los emigrados a Magalhaes Lima y Gumersindo de la Rosa en $O$ Seculo, (13-8-1883, 16-8-1883 y 18-8-1883). El periódico de Magalhaes Lima actuó como portavoz de las reclamaciones de los exiliados españoles. Vid. Despacho del encargado de negocios interino en Lisboa al Ministro de Estado, (17-8-1883), AMAE, H 2868.

${ }^{28}$ Encargado de negocios interino en Lisboa al Ministro de Estado, (20-8-1883), AMAE, H 2868.

${ }^{29}$ Según la Direction de la Sûreté Générale los internados fueron 121 oficiales. Ministère de L'Interieur, (13-

9-1883), en Archives Nationales de France [ANF], F/7, 12695.

${ }^{30}$ RODRÍGUEZ SOLÍS, Enrique: Memorias de un revolucionario, Madrid, Plutarco, 1931, p. 163.

31 Sobre la rebelión de Santo Domingo de la Calzada, Vid. DÍEZ MORRAS, Javier: La sublevación republicana del regimiento "Numancia" de 1883. Historia de la Sargentada de Santo Domingo de la Calz̧ada, Logroño, Piedra de Rayo, 2009.
} 
treinta y nueve restantes se adentraron en Francia ${ }^{32}$, donde se decretó su internamiento en Angoulême ${ }^{33}$.

Los cabos, soldados y algunos sargentos procedentes de Badajoz, mientras tanto, permanecieron en Portugal y fueron repartidos en tres depósitos: cuatrocientos en Sacaven. Trescientos en Peniche y los restantes en Torresvedras ${ }^{34}$. A finales de agosto se les comunicó que el Gobierno español estaba dispuesto a concederles el indulto. El único escollo radicaba en la influencia que podían ejercer los sargentos para que no lo pidieran. El vicecónsul español consideraba que haría mal efecto, si la noticia se hacía pública, que fuese insignificante el número de los acogidos a indulto ${ }^{35}$. La medida, sin embargo se demoró hasta finales de noviembre. Su alcance se limitó a los cabos y soldados ${ }^{36}$. Al concluir el plazo para solicitarlo, el número total de indultados ascendía a $504^{37}$. Por lo tanto, en torno a 220 permanecieron en los depósitos portugueses junto a los sargentos que no habían sido conducidos a Francia. A ellos debían sumarse algunos oficiales que pudieron escapar de Elvas y ocultarse ${ }^{38}$.

\section{LA VIDA EN LOS DEPÓSITOS DE INTERNAMIENTO}

La emigración republicana de 1883 se completó con algunos militares y civiles implicados en la organización del movimiento. Miguel Pérez, secretario de la ARM, Ernesto de la Guardia y Ginard de la Rosa, redactores de El Porvenir, y Ricardo López, representante de Ruiz Zorrilla, huyeron a Ginebra, donde se encontraba el jefe revolucionario ${ }^{39}$. Desde este punto se decidieron las bases para la organización de la emigración. Con este fin, los jefes de las sublevaciones de Badajoz y la Seo de Urgell se trasladaron a Suiza. Uno de los puntos cruciales a debatir era el destino que debía darse a los fondos de Badajoz. Zorrilla determinó que sirvieran para socorrer al conjunto de los emigrados ${ }^{40}$. El abogado Rubén

\footnotetext{
32 Existen dos relaciones de los 17 sargentos internados en Francia procedentes de La Seo de Urgel en AMAE, H 2868.

33 Vid. Departamento de La Charente al Ministerio del Interior, (Angoulême, 6-9-1883), ANF, F/7, 12695.

${ }^{34}$ Encargado de negocios de España en Lisboa al ministro de Estado en Madrid, (L8-8-1883), AMAE, H 2868.

35 Vicecónsul de la Legación de S. M. Católica en Lisboa al Ministro de Estado, (22-8-1883).Ibídem.

36 Vid. Gaceta de Madrid, no 331, 27-11-1883, p. 623; y despacho del ministro de Estado al embajador de España en París, (30-11-1883), Archivo General de la Administración [AGA], 54/5725, leg. 210, nº 573.

37 Ministerio de Estado al Ministerio de la Guerra (7-1-1884), AMAE, H 2868. En enero de 1884 la medida se extendió a los cabos y soldados procedentes de la Seo de Urgell. Vid. Ministerio de Estado a Embajador de España en París, (11-1-1884), AGA, 54/5725, leg. 210, nº 15.

38 PRIETO Y VILLARREAL, Emilio: Ruir. Zorrilla desde su expulsión de España hasta su muerte (1875-1895). Recuerdos políticos, Madrid, M. Romero, 1903. pp. 118-119.

${ }^{39}$ PRIETO Y VILLARREAL, Emilio: op. cit. p. 151. GARCÍA LADEVESE, Ernesto: op. cit. pp. 129-130.

${ }^{40}$ MUÑOZ EPELDE, Melchor: op. cit. pp. 151-152.
} 
Landa fue designado tesorero. Ezequiel Sánchez se dirigió a Orán, donde organizó los residuos de la emigración cantonal en forma de comités republicanos zorrillistas ${ }^{41}$.

Los oficiales que habían actuado como jefes del movimiento conservaron la autoridad en sus respectivos depósitos, de modo que su organización reflejaba la jerarquía militar. Para entenderse con militares, o para mandarlos -explicaba Muñoz Epelde- hay que ser militar, y en este último caso, siempre de mayor graduación que los que hayan de obedecer ${ }^{42}$. El coronel Foncuberta actuó como jefe del depósito de Angoulême. En octubre se creó en Rennes una Junta de Administración y Gobierno de la emigración de Badajoz presidida por Asensio Vega. El capitán Rubio Báez consideraba que esa junta no era expresión del procedimiento democrático que como emigración republicana debían observar. Decidió, por ello, no reconocerla, si bien tampoco se enfrentó a ella ${ }^{43}$. Su conducta fue poco imitada. La necesidad de permanecer junto al compañero, la dependencia de los socorros y, también, el reconocimiento de la jefatura como algo natural dentro de un grupo fuertemente corporativo, aconsejaban a la mayoría integrarse en ella.

A grandes rasgos, pueden trazarse cuatro características fundamentales de la emigración zorrillista a partir de este momento: la precariedad económica, el sometimiento a las jefaturas de los depósitos (y de éstas a las directrices de Ruiz Zorrilla), una movilidad geográfica limitada y la inexistencia de perspectivas de integración en el país de acogida. La primera es la raíz de las restantes. Para su supervivencia, los emigrados contaban con cinco posibles fuentes de ingresos: los fondos de Badajoz, repartidos en forma de socorros mensuales; el subsidio de un franco diario que el gobierno francés entregaba a los emigrados políticos ${ }^{44}$; el trabajo, las ayudas familiares y el patrimonio propio. Las dos últimas, a menudo, eran inexistentes.

Rubén Landa se ocupaba de los primeros. La mayor parte de los fondos fueron invertidos en el Banco Transatlántico que, a su vez, había proporcionado en épocas anteriores préstamos para la revolución a Ruiz Zorrilla ${ }^{45}$. Landa figuraba como titular de 225 Obligations Egyptiennes que representaban algo más de ochenta mil francos ${ }^{46}$. Los restantes estaban a su disposición para los gastos inmediatos de la emigración. Al margen

${ }^{41}$ Vid. VILAR, Juan Bta.: Los españoles en la Argelia francesa (1830-1914), Madrid, Universidad de Murcia, 1989, pp. 293-296.

${ }_{42}$ MUÑOZ EPELDE, Melchor: op. cit. p. 204.

43 Vid. RUBIO BÁEZ, Daniel: op. cit.

${ }^{44} \mathrm{El}$ número de refugiados españoles que cobraban el subsidio era de 228 a finales de 1883. Vid. "État numérique (au 20 Septembre 1883) des réfugiés Espagnols internés en France qui reçoivent une subvention d'un franc par jour" en ANF, F/7, 12695.

45 Vid. Telegrama del Embajador de España en París al Ministro de Estado, (24-4-1884), AGA, 54/5725, Leg. 211.

46 Vid. "Cuenta de los fondos de la emigración de Badajoz desde el día $1^{\circ}$ hasta el 31 de mayo de 1884", que se incluye en la carta de Rubén Landa a Ruiz Zorrilla, (Rennes, 19-6-1884), AHFE/AMRZ, Exilio 43, C 10. 
de lo entregado antes de cruzar la frontera y una vez en Portugal, la Junta decidió distribuir cuatro pagas de los dos empleos superiores a Jefes, oficiales y sargentos ${ }^{47}$.

El socorro a los paisanos quedó a discreción de Landa. Éste ideó un sistema por el que se equiparaban los empleos civiles a los militares. El ex alcalde de Badajoz, Vicente Martínez, propietario y fabricante de vinos, recibió las 2800 pesetas que correspondían a un comandante. Lo mismo cobró el presidente del comité republicano federal, Luis Díaz, veterinario con establecimiento. A un maestro carpintero se le equiparaba con un teniente. Dos cavadores de viñas, un boyero y dos peones de albañiles recibieron las 700 pesetas que correspondían a un sargento segundo ${ }^{48}$. Esta asimilación deja traslucir una concepción de la sociedad en la que la riqueza o el prestigio asociado a una profesión equivalían a mérito y, sobre todo, a jerarquía.

En total recibieron ayuda 59 civiles. No todos ellos residían en los depósitos franceses. Por ello, Landa se trasladó, sin permiso de la Prefectura ni de la Junta de emigrados, a Portugal. Su propósito era abonar sus pagas a los militares y civiles que permanecían allí. Regresó dos meses más tarde, tras haber sido detenido y confinado por las autoridades lusas ${ }^{49}$. Estos hechos desencadenaron una guerra entre los militares y civiles del depósito de Rennes. Los primeros juzgaban desproporcionado lo entregado a los paisanos. Al ser Landa el único titular de los fondos, durante su encierro habían estado privados de esos recursos. Por otra parte, sospechaban que había favorecido a personas ajenas a la insurrección ${ }^{50}$. Por ello, le pidieron que renunciara a la depositaría. Los paisanos explicaba Landa- temiendo un completo olvido de ellos para socorrerlos, me exigen que no la entregue ${ }^{51}$.

En todo ello subyacía la competencia por unos recursos que poco a poco se agotaban: en enero de 1884 los emigrados disponían de 108.193 francos. En mayo esa cantidad se había reducido a 71.000. Un mes más tarde quedaban 57.68052. Para colmo, la crisis desencadenada en Egipto tras la batalla de El Teb provocó la caída de las acciones depositadas en la Banca Trasatlántica ${ }^{53}$. Dado que los militares habían protagonizado el movimiento, consideraban que los civiles no eran acreedores de una gratificación equiparable a sus méritos. Sin embargo, no faltaron oficiales que tomaron partido por

\footnotetext{
${ }^{47}$ Rubén Landa a Ruiz Zorrilla, (Rennes, 10-5-1884), AHFE/AMRZ, Exilio 43, C 10.

48 Vid. "Relación de los paisanos pertenecientes a la misma con expresión de las cantidades que se han percibido", incluida en la anterior carta.

49 Junto a él fueron deportados once civiles y un militar. Ministro de Estado al Embajador de España en París, (8-4-1884), AGA, 54/5725, leg. 210. nº 172.

50 "Contienda entre los señores Vega y Landa", op. cit. hojas 20-31.

51 Ibidem.

52 Vid. Cartas de Rubén Landa a Ruiz Zorrilla (Rennes, 16, 19 y 21-6-1884; París, 27-7-1884) en AHFE/AMRZ, Exilio 43, C 10.

53 Vid. Rubén Landa a Ruiz Zorrilla (Rennes, 19-6-1884), en AHFE/AMRZ, Exilio 43, C 10.
} 
Landa ${ }^{54}$. No puede por ello hablarse de un conflicto puramente corporativo. Landa terminó renunciando a la tesorería y, por mediación de Nicolás Salmerón y de Ruiz Zorrilla, pudo trasladarse a París como redactor de El Correo de Ultramar ${ }^{55}$. En diciembre, el dinero prácticamente se había agotado ${ }^{56}$.

Adolfo Expósito describió con detalle la situación de los emigrados al llegar a Rennes. Alquiló dos cuartos junto a tres compañeros. Cada uno tenía una sola cama que compartían separando el jergón del colchón. Pagaban 75 céntimos por cabeza. Dado que hablaba francés, se convirtió sin quererlo en asistente del coronel Vega, quien pretendía tener un limpiabotas, un criado y un intérprete, por la sencilla cosa del estipendio de dos cafés al día ${ }^{57}$. Debe entenderse que el exilio significaba el abandono de una posición profesional y social. Los jefes del ejército contaban con un prestigio vinculado a determinados privilegios. Entre otros, el de tener asistentes militares. Años más tarde, el periodista López Lapuya recordaba que Asensio Vega ha[bia] tenido que poner sus hijas a servir lo mismo que si no fueran señoritas ${ }^{58}$. Obviamente, en su nuevo contexto ya no lo eran.

No eran mejores las circunstancias de los procedentes de la Seo de Urgell:

Por efecto de la falta de recursos y del estado de miseria verdaderamente aflictivo en que se encuentran especialmente los carabineros que residen en Angoulema. [...] la mayor parte de los procedentes de la clase de tropa se hallan muy desalentados y sin la intervención del Teniente Gerónimo Pou, dichos Carabineros hubieran pedido ya el indulto ${ }^{59}$.

La precariedad económica de los emigrados se agravó extraordinariamente a partir de enero de 1885, cuando el Gobierno francés decidió eliminar los subsidios ${ }^{60}$. A la vez, se levantaron las restricciones para abandonar los depósitos, sin más límites que la prohibición de residir en las poblaciones fronterizas ${ }^{61}$. En cualquier caso, las autoridades departamentales no fueron excesivamente celosas en la vigilancia de esa restricción ${ }^{62}$. A partir de entonces los emigrados dependieron exclusivamente de su trabajo y de la ayuda

\footnotetext{
${ }^{54}$ EXPÓSITO, Adolfo: op. cit. s/n.

55 Vid. Rubén Landa a Ruiz Zorrilla (París, 2-9-1884), en AHFE/AMRZ, Exilio 43, C 10.

56 "Demostración de las cantidades recibidas y distribuidas en el tiempo que ha sido Depositario el que suscribe [Miguel Caparrós]” en AHFE/AMRZ, Exilio 43.

${ }^{57}$ EXPÓSITO, Adolfo: op. cit.

${ }^{58}$ LÓPEZ LAPUYA, Isidoro: La bohemia española en París a finales del siglo pasado, París, Casa Editorial FrancoIbero-Americana, s/f. pp. 118-119.

${ }^{59}$ Informe, s/f [1883], AGA, 54/5725, leg. 210.

${ }^{60} \mathrm{Su}$ importe ascendía anualmente a 120.000 francos. GONZÁLEZ CALLEJA, Eduardo: "Republicanos", op. cit. p. 197.

61 Embajada de España en París a los cónsules de España en Bayona, Perpignan, Cette y Toulouse, (7-31886), AGA, 54/5823, Leg. 529.

${ }^{62}$ Cónsul de España en Burdeos al embajador de España en París, (6-12-1883), AGA, 54/5794, nº 12; y Pérez de Brey al conde de Morphy, (1-12-1886), AGP, Cajón 26, Exp. 7.
} 
del partido. Sólo la necesidad de permanecer junto a los compañeros fijó a muchos de ellos en los depósitos de Rennes y Angoulême. Otros se desplazaron allá donde creían poder encontrar mejores oportunidades. Rubio Báez, por ejemplo, se trasladó a Burdeos, de donde se marchó:

convencido que los franceses en $1^{\text {er }}$ término dan las colocaciones y el trabajo a los compatriotas antes que a los extranjeros [...] y falto de relaciones influyentes que pudieran colocarme trabajando donde y en lo que buenamente desempeñar pudiera, convencido repito de mi inutilidad en Francia, sobre todo porque no sé oficio alguno y menos entiendo de ninguna clase de trabajos rudos, en razón a que desde mis primeros años no me ocupé en otra cosa que estudiar y la curia hasta que a la edad de 17 años entré en la carrera de $\operatorname{armas}^{63}$.

Su testimonio ofrece algunos rasgos importantes para caracterizar a la emigración de 1883: las limitaciones laborales tenían, en primer lugar, un componente xenófobo. En segundo lugar, desconocían todo trabajo fuera de la milicia. Un año más tarde, el capitán exiliado Carlos Casero, al entrevistarse con Ruiz Zorrilla en París, le confesó que no tenía más oficio que el de mandar soldados ${ }^{64}$. Por otra parte, si en las ciudades del interior de Francia existía una red de solidaridades tejida por los restos de emigraciones anteriores, no bastaba para asimilar a los más de doscientos refugiados procedentes del movimiento de agosto. La respuesta de Ruiz Zorrilla a esta situación fue doble. De un lado, sus contactos en la política francesa iniciaron una campaña en favor de los refugiados. Alfred Naquet y Edouard Lockroy se convirtieron en los principales valedores de la emigración republicana ${ }^{65}$.

Por otro, inició una suscripción nacional e internacional con la que socorrer, en nombre del partido, a sus emigrados. El objetivo era suplir los 30 francos mensuales del gobierno francés y auxiliar con una pensión a las viudas de los militares ejecutados. En España, la prensa del partido y un comité presidido por Laureano Figuerola se ocuparon de las gestiones. En el extranjero contó con el apoyo de periódicos y personalidades políticas francesas e italianas. El ex diputado Antonio de la Calle, desde Suiza, informó a Ruiz Zorrilla de los contactos establecidos con Clemenceu o con Cancio Garibaldi y sobre la buena disposición de periódicos como La Justice o Il Mare, de Génova, para canalizar la

\footnotetext{
${ }^{63}$ RUBIO BÁEZ, Daniel: op. cit.

${ }^{64}$ CASERO, Carlos: Recuerdos de un revolucionario, Valencia, Sempere y Cía., s/a. p. 69.

${ }^{65}$ GARCÍA LADEVESE, Emilio: op. cit. pp. 158-163.
} 
solidaridad internacional hacia los republicanos españoles ${ }^{66}$. Según el mismo Zorrilla, Juliette Adam había iniciado una suscripción entre sus amigos a 1000 fr. por barba ${ }^{67}$. El problema consistía en mantener el ritmo de los ingresos después de los primeros entusiasmos. Con frecuencia, el propio Ruiz Zorrilla tuvo que suplir con su patrimonio personal los gastos de la emigración ${ }^{68}$.

Ernesto de La Guardia y García Ladevese fueron los encargados por el jefe revolucionario de repartir las ayudas entre los emigrados. Éstos le devolvían un recibo, que aprovechaban para hacer profesión de fe republicana, y para comunicar sus problemas diarios $^{69}$. Estos documentos permiten rastrear los pasos de los emigrados. En primer lugar, se comprueba una tendencia a abandonar el depósito de Rennes. Los problemas de convivencia y la necesidad de encontrar trabajo provocaron una notable dispersión hacia otras ciudades desde finales de $1884^{70}$. El jefe de cada nuevo núcleo era, habitualmente, el oficial de mayor jerarquía.

El año siguiente habían aparecido nuevos depósitos de emigrados. En junio, 31 refugiados residían en Burdeos. En octubre eran 36. Durante el mismo periodo el número de emigrados se había reducido de 16 a 10 en Angoulême. Montauban mantuvo en esos meses 52 exiliados. De los 41 que permanecían en Rennes en Agosto, solo quedaban 36 en octubre. París, Ginebra, Béziers, Marsella y Orán acogían núcleos de entre 4 y 7 refugiados. En poblaciones de la frontera como Narbona, San Juan de Luz o Hendaya, sin duda esquivando el control de las autoridades, aparecen dispersos otros pocos ${ }^{71}$. Incluso algunos probaron fortuna emigrando a América ${ }^{72}$. Fue el caso de Gerónimo Pou, que llegó a

\footnotetext{
${ }^{66}$ Antonio de la Calle a Ruiz Zorrilla, (28-11-1883), AHFE/AMRZ, Exilio 9, C 84. La campaña se extendió a otros medios como La Justice, Le Figaro, La Republique Anticlericale, La Gazzeta di Torino y asociaciones como la Societé Oubvriere Parisien, el Groupe Democratique Italien, la Union Fraternale y la Union Helléno-Latine. Buschalion a Ruiz Zorrilla (21-11-1883). AHFE/AMRZ, Exilio 8, C 75.

${ }^{67}$ Carta de Ruiz Zorrilla a María [Pereira de Buschental], (s/f, 1883), AGP, Alfons XII, Cajón 18, Exp. 1.

68 Vid. "Cuenta de las cantidades suplidas por D. Manuel Ruiz Zorrilla para auxilio de los emigrados", (Londres, 8-9-1885), en AHFE/AMRZ, Exilio 43, C 112.

${ }^{69}$ Todos los recibos en AHFE/AMRZ, Exilio 47, C 172. Las cuentas de los repartos entre 1885 y 1886 se conservan en AHFE/AMRZ Exilio 43, C 53 y C 54.

${ }^{70}$ El Prefecto de Ille-et-Villaine informó al Ministro de Interior que entre los refugiados de Rennes, había vingt deux cultivateurs qui ont vainement cherché de l'occupation dans cette ville, por lo que solicitaban su traslado a Orán. Prefectura de Ille-et-Villaine al Ministro del Interior, (Rennes, 22-9-1883). Trece de los civiles internados en Rennes abandonaron el depósito sin autorización en enero de 1884 y se dirigieron a Portugal. Prefectura de Ille-et-Villaine al Ministro del Interior, (31-1-1884), ANF, F/7, 12695.

${ }^{71}$ Sobre la dispersión geográfica de los emigrados, Vid. José Fernández al conde Morphy, (Madrid, 2-3-1884), AGP, Cajón 18, exp. 4.

72 PRIETO Y VILLARREAL, Emilio: op. cit. p. 275. El Cónsul de España informó al Embajador de España sobre un emigrado que se había trasladado a México "empleado por el gobierno de aquella República", (21-9-1887), AGA, 54/5834, Leg. 568, nº 34.
} 
convertirse en Cónsul de Guatemala en París ${ }^{73}$. En mayo de 1886, los mayores depósitos seguían siendo Montauban (48), Burdeos (30) y Rennes (30).

Los que pudieron, como Muñoz Epelde, marcharon a Portugal. El antiguo secretario de la Junta revolucionaria de Badajoz fue comisionado para ayudar desde allí a la conspiración. Se instaló en Elvas hasta que el gobierno [...] dispuso internarnos a los pocos emigrados que nos encontrábamos cerca de la frontera. Posteriormente consiguió regresar a Elvas, donde se reencontró con su familia. Es necesario llamar la atención sobre el fenómeno de la reagrupación de muchas familias en el exilio. En septiembre de 1883 el Ministerio del Interior había acordado conceder a las mujeres que se habían trasladado junto a los refugiados el mismo subsidio que ellos cobraban ${ }^{74}$. En junio había en Montauban dos familias de emigrados con siete miembros (entre ellas la de Foncuberta), dos de cinco, seis de cuatro componentes y seis más de tres. Había, además, otros seis matrimonios ${ }^{75}$. En Rennes, 25 emigrados convivían con algún miembro familiar. El número total de mujeres e hijos era de $49^{76}$.

Las limitaciones laborales hacían extremadamente duro el día a día de los emigrados. En Burdeos, Algunos de los que residían en Montauban describieron su experiencia a Ruiz Zorrilla con total sinceridad:

La situación de la mayoría de los que hemos quedado en esta villa, es cada día más precaria, ya porque carecemos de todo auxilio, ya también porque $[. .$.$] no$ encontramos otra ocupación que el rudo trabajo del campo; que desconocemos y no podemos soportar por la edad o por no haberlo hecho nunca aquí, es imposible emplearnos, ni en barrer las calles, cosa, que en verdad, diría bien poco en favor del Ejército Español y del Partido que representamos; si fuéramos carlistas, no careceríamos de nada entre los legitimistas que constituyen la mayor y mas bien acomodada parte de la población: pero somos republicanos, y no podemos esperar otra cosa que el plato de sopa, que alguna vez pueda ofrecernos, el tan pobre como honrado obrero.

Los periódicos que dicen ser amigos, con tanto hablar de suscripciones generales, de remesas efectuadas de fondos y de que el Partido atiende y atenderá a los emigrados mejor que lo hacía el Gobierno Francés, no hacen más que propagar mentiras, que [...] empeoran nuestra situación, impidiendo nos socorra algún amigo, y hasta nuestras propias familias, que no pueden formarse idea exacta de la miserable existencia que arrastramos, y esto, no hace maldita la gracia al que no tiene otro auxilio que las ilusiones sostenidas, por la farsa periodística ${ }^{77}$.

\footnotetext{
${ }^{73}$ LÓPEZ LAPUYA, Isidoro: op. cit. pp. 117.

${ }^{74}$ Ministerio del Interior a la Prefectura de Tarn-et-Garonne, (Paris, 19-9-1883), ANF, F/7, 12695.

${ }^{75}$ Francisco Foncuberta a Ruiz Zorrilla (Montauban, 21-6-1885), Exilio 47, C 172.

76 "État nominatif des femmes et des enfants des réfugiés espagnols, en résidence à Rennes" (27-11-1883), ANF, F/7, 12695.

${ }^{77}$ Carta s/a [incompleta] a Ruiz Zorrilla (Montauban, 22-3-1886), AHFE/AMRZ, Exilio 43.
} 
Entre los refugiados de Burdeos, la mayoría se dedicaban a barrer las calles por 1775 francos al día, o a la venta ambulante ${ }^{78}$. Los dieciséis emigrados que quedaban en Angoulême padecían una situación semejante. En una carta enviada a un periódico francés, manifestaban estar dans la plus affreuse misère, sans argent, presque sans pain después de la retirada del subsidio. Tras pedir trabajo al Consejo Municipal, se les ofreción trabajar côte à côte avec les reprís de justice pour un salaire de soixante centimes par jour. Al igual que los refugiados de Montauban, comparaban su suerte con la de los carlistas. Nous no demandons que du travail, concluían- du travail pour vivre ${ }^{79}$.

\section{CONTROL DE LOS EMIGRADOS A TRAVÉS DE LOS SUBSIDIOS}

Ruiz Zorrilla y los jefes de los depósitos no recibían de buen grado las quejas de los refugiados, y aún peor las críticas, cuando éstas se dirigían a la prensa española. Desde su perspectiva, su comportamiento debía subordinarse a los intereses del partido. La disciplina y la unidad de acción eran, desde este punto de vista, indispensables para no perturbar la marcha revolucionaria. Al emigrado se le pedía resignación, colaboración con la causa en la medida de sus facultades y un comportamiento digno. Los gestiones de Ruiz Zorrilla para lograr un trato favorable de los políticos franceses hacia los exiliados podía destruirse si éstos incurrían en acciones censurables, aunque una necesidad extrema les llevara a ello.

La frágil situación de los refugiados ayudaba a que las normas de conducta fueran observadas. En un contexto marcado por la escasez, mantenerse dentro del grupo era una necesidad tanto moral como material para sobrevivir. Cuando Manuel Muñiz, del depósito de Rennes, sustrajo dos pares de calcetines y una cuchara de hueso en un bazar de la localidad, la Junta de administración formó un tribunal de honor. Entre otros acuerdos, decidieron expulsarlo de la emigración y protestar en la prensa en caso de que el asunto se hiciera público. A la vez, el Sr. Vega y demás masones, se interesa[ron] personalmente cerca de las autoridades judiciales de Rennes, para que secretamente vieran el medio de librarlo de las garras de la justicia ${ }^{80}$.

El mismo mecanismo funcionaba para amortiguar las disidencias. Poder marcar los límites de inclusión y exclusión permitía influir eficazmente en la coherencia del grupo. Ante la dificultad de encontrar trabajo, el socorro del partido era lo único que separaba la escasez de la miseria. Esa ayuda era canalizada desde Ruiz Zorrilla hasta los jefes de los

\footnotetext{
78 Vid. los informes individuales realizados por la Prefectura de la Gironde (s/f) en ANF, F/7, 12695.

79 "Les Proscrits Espagnols en France", Le Cri du Peuple, (25-8-1885).

${ }^{80}$ RUBIO BÁEZ, Daniel: op. cit. Un caso similar ocurrió en 1890, cuando un emigrado presentó en el banco una letra falsa. Vid. El País, (5-10-1890).
} 
depósitos que le representaban. Así se explica que un emigrado de Angoulême tuviera que firmar la siguiente exposición:

Yo Ceferino Carrasco: emigrado republicano comprometo mi palabra honrada a nuestro ilustre Jefe Exmo. Sr. D. Manuel Ruiz Zorrilla de que no [...] escribiré ni hablaré en contra de dicho Jefe y del partido. Asimismo declaro que respetaré todas sus órdenes aunque sean estas comunicadas por los oficiales de este depósito guardándoles las atenciones que como tales se merecen ${ }^{81}$.

No debe, sin embargo, subestimarse la adhesión al partido revolucionario y a su máximo dirigente como un factor que asegurara la unidad y la obediencia. El único enemigo que reconocían la mayor parte de los exiliados era la monarquía. Las disidencias en la emigración partían generalmente de aquéllos militares que no pertenecían a la ARM. Fue el caso de Julio Reboul, quien, según Rubio Báez, quería muy mal a los republicanos en general, y muy particularmente a todos los que tomamos parte activa en el movimiento de Badajoz, porque dice le hicimos perder su carrera. El ex comandante tuvo que abandonar, sucesivamente, los depósitos de Rennes, Montauban y Angoulême. Allí se le formó juicio de honor por ser saberse que por doquiera pasa hace propaganda contra la idea republicana, rebajando y desacreditando hasta lo grosero a nuestro Ilustre Jefe $e^{82}$.

Existía una consigna clara: la única solución definitiva para los emigrados era el triunfo de la Revolución, que les aseguraría el regreso a España como vencedores. Las alternativas eran continuar en el exilio o esperar el perdón del gobierno. Por ello, uno de los deberes de los emigrados era contribuir al éxito de la causa. Algunos, como el capitán Higinio Mangado y el capitán Melchor Muñoz, formaron parte del “estado mayor” de Ruiz Zorrilla en Ginebra ${ }^{83}$. El primero, además, protagonizó el único chispazo del nuevo movimiento proyectado en abril de 1884, que le costó la vida ${ }^{84}$. Las autoridades españolas siempre consideraron los movimientos en los depósitos como un síntoma de acontecimientos revolucionarios inminentes. Sin embargo, lo que Ruiz Zorrilla les pedía era que permanecieran a la expectativa ${ }^{85}$. Así, en septiembre de 1884 tuvo que escribir a los depósitos para prohibir terminantemente:

\footnotetext{
${ }^{81}$ Ceferino Carrasco a Ruiz Zorrilla, (Angoulême, 17-6-1885), AHFE/AMRZ, Exilio 43, C 172.

82 RUBIO BÁEZ, Daniel: op. cit.

83 PRIETO VILLARREAL, Emilio: op. cit. pp. 146-147.

${ }^{84}$ Sobre la partida de Mangado, Vid. "Expediente instruido en el Consulado General de España en Bayona con motivo de la formación de la partida Mangado" (7-5-1884), en Consulado General de España en Francia al Ministerio de Estado, (7-5-1884), AGA, 54/5725, leg. 210.

${ }^{85}$ Cartas de Ruiz Zorrilla a Foncuberta y Asensio Vega, (Londres, 22-4-1885), AGP, Cajón 26, exp. 1/A.
} 
que los jefes y oficiales emigrados intenten acto alguno revolucionario, cualesquiera que sean las promesas que les hagan sus compañeros de España [...] Dé V. pues de baja en la lista de emigrados, para hoy y para el porvenir a los que hablen o se agiten en aquel sentido y deme cuenta de sus nombres para borrarles del "Gran Libro"86.

Los socorros, por tanto, también funcionaron en este caso como un mecanismo eficaz de control. La situación de la mayoría de los exiliados no les permitía ser verdaderamente útiles para una revolución que debían efectuar los militares desde el interior. Les correspondía, eso sí, resistir a las ofertas del gobierno para vender información (de la que generalmente no disponían) y ayudar, en lo posible, a descubrir a los espías que se infiltraban entre ellos. Aunque en los testimonios de los emigrados abundan los capítulos relativos a espionaje y contraespionaje, no siempre evitaron lo primero ni lograron lo segundo ${ }^{87}$.

\section{DEL INDULTO DE 1885 A LA AMNISTÍA DE 1891}

En esas circunstancias la única posibilidad de regresar a España pasaba por la concesión de un indulto o la promulgación de una amnistía. La actitud de Ruiz Zorrilla al respecto evolucionó notablemente a lo largo de 1885. En septiembre del año anterior el jefe revolucionario indicaba a Francisco Foncuberta la necesidad de evitar que se hablara de una hipotética amnistía:

además de la vergüenza de que una parte de los oficiales la aceptasen, nos traería el inmenso perjuicio de llevar el desaliento a los comprometidos en España con la pintura de sufrimientos que exagerarían de propósito para justificar su cobardía y falta de abnegación ${ }^{88}$.

Ante la posibilidad de solicitar indultos particulares, Zorrilla se había mostrado igualmente severo ${ }^{89}$. Sin embargo, cuando en diciembre de 1885 el gobierno de Sagasta publicó un decreto ofreciendo el indulto por delitos políticos ${ }^{90}$ la situación había cambiado radicalmente. Los sucesivos fracasos insurreccionales y el peso, cada vez más insoportable para el partido, de la emigración, motivaron el cambio de actitud. En esas circunstancias era

\footnotetext{
${ }^{86}$ Carta-circular Ruiz Zorrilla a Francisco Foncuberta (Londres, 24-9-1884), AGP, Cajón 26, Exp. 1/A.

87 PRIETO Y VILLARREAL, Emilio: op. cit. pp. 147-150 y 305-306.

88 Carta-circular de Ruiz Zorrilla a Francisco Foncuberta, op. cit.

89 Ceferino Carrasco prometió solemnemente a Zorrilla no haber "solicitado el indulto del Gobierno Español" ni hacerlo en el futuro. Vid. Ceferino Carrasco a Ruiz Zorrilla, op. cit.

${ }^{90}$ Vid. Real Decreto de 9-12-1885, Gaceta de Madrid, no 334, 10-12-1885, p. 822.
} 
imposible pedir resignación o apelar al patriotismo de los refugiados. Es una infamia escribía en marzo de 1886- el decir que yo aconsejo a los emigrados y les escribo para que no pidan el indulto ${ }^{91}$. De hecho, envió circulares a los nueve depósitos recomendando regresar a España a aquellos que carecieran de recursos ${ }^{92}$.

Según las instrucciones del Ministerio de Estado, la emigración debía reducirse al número estrictamente indispensable, excluyendo a los jefes militares que se hayan hecho culpables de sedición o rebelión al frente de sus tropas ${ }^{93}$. Los que se encontraban sometidos a la jurisdicción militar podían promover instancias a la regente en súplica de que se digne concedérselos como gracia especial ${ }^{4}$. La intención del gobierno español consistía en forzar a los emigrados republicanos a regresar bajo esta última condición, presionando a su vez a las autoridades francesas para que retiraran el subsidio o extrañaran a los departamentos del noreste a quienes rehusaran el perdón ${ }^{95}$. El gobierno francés, por su parte, se comprometió a fijar el río Dordogne como límite para los que se encontraran en este caso, y el Loira para quienes fueran considerados especialmente peligrosos por sus homólogos españoles. Los que fueran considerados especialmente peligrosos por sus homólogos españoles ${ }^{96}$.

La mayor parte de los emigrados de 1883 solicitaron el indulto ${ }^{97}$. Pero el número de los que lo rechazaron no fue insignificante. Así, el embajador español pidió el internamiento inmediato de treinta y tres emigrados que habían hecho pública su actitud en El Progreso, órgano del Partido Republicano Progresista ${ }^{98}$. Como respuesta, Moret desplegó una intensa actividad de hostigamiento a los emigrados, formulando constantes reclamaciones al gobierno francés ${ }^{99}$. Todavía en marzo de 1887 se solicitó la retirada del subsidio a los once refugiados, procedentes de Badajoz, que quedaban en Rennes ${ }^{100}$. Un triple control (el partido, el gobierno francés y el español) limitaba, de este modo, el comportamiento de los emigrados.

\footnotetext{
${ }_{91}$ Porvenir [Seud. Ruiz Zorrilla] a Andrés Sanz, (24-3-1886), AGA, 54/5823, Leg. 529.

92 "La Actitud de Ruiz Zorrilla", El Liberal, (26-1-1883).

${ }^{93}$ Ministerio de Estado a Embajada de España en París (14/12/1885), AGA, 54/5834, Leg. 568, no 567; y Cónsul de España en Burdeos a Embajador de España en París, (19-12-1885), AGA, 54/5794, n 18.

${ }^{94}$ Consulado de España en Burdeos a Embajada de España en París, (23-12-1885), AGA, 54/5834, Leg. 568, $n^{\circ}$ 19. Embajador de Francia en Madrid al Ministerio de Asuntos Exteriores, (12-12-1885), Archives Diplomatiques de France, en La Courneve, (París), [ADFP], Vol. 907, no 90.

${ }^{95}$ Embajada de España en París al Presidente del Gobierno de Francia (24-12-1885), ADFP, Vol. 907.

${ }^{96}$ Ministerio de Asuntos Exteriores de Francia al embajador de España en París, (28-2-1886), ADFP, Vol. 908.

97 MUÑOZ EPELDE, Melchor: op. cit. p. 214. Algunas de las solicitudes y concesiones de indulto se conservan en AGA, 54/5823, Leg. 529 y 54/5834, Leg. 568.

98 Embajador de España en París al Presidente del Consejo de Ministros de Francia, (4-2-1886 y 18-2-1886), ADFP, Vol. 908.

${ }^{99}$ Demandas de este tipo se suceden en los tomos 908 a 911 del ADFP.

${ }^{100}$ Embajada de España en París al Ministro de Asuntos Exteriores de Francia, (19-3-1887), ADFP, Vol. 911.
} 
Pocos meses más tarde, la emigración republicana volvió a incrementarse. El fracaso de la sublevación del general Villacampa en septiembre de 1886 provocó la fuga de los implicados. Cada uno trató de alcanzar la frontera como pudo, apoyándose tanto en su círculo familiar como en las redes del partido. La mayor parte fueron capturados por las autoridades $^{101}$. El destino de los restantes fue Francia: el comandante Emilio Prieto logró escapar junto al alférez Sanz en ferrocarril después de permanecer escondido algunos días en Madrid. En San Juan de Luz fue obligado por el comisario de Policía a optar entre los depósitos de Rennes y Angulême para fijar su residencia. Optó por la segunda población, a la que ya habían llegado algunos otros náufragos de la rebelión.

De nuevo, los sedimentos de anteriores emigraciones facilitaba la supervivencia de los nuevos refugiados: un antiguo combatiente carlista, reconvertido en republicano, regentaba allí una fonda donde acogía, entre otros emigrados, a dos de los oficiales sublevados en Badajoz. Pocos días más tarde llegaron desde Cataluña al mismo punto un militar y siete civiles implicados en el movimiento. Las autoridades francesas les permitieron alojarse en las celdas de la cárcel. Mientras, otros compañeros dormían en un camaranchón tan inhospitalario, que sólo la más extrema necesidad lo hacía tolerable ${ }^{102}$.

Con o sin permiso de las autoridades francesas, la mayoría se dirigieron a París. La presencia de Ruiz Zorrilla convirtió a la capital del Sena en el destino predilecto de los emigrados. Allí llegó también el capitán Casero. En enero de 1887, doce sargentos capturados tras la rebelión de Villacampa lograron escapar de las prisiones junto a sus vigilantes. Tras ocultarse en Madrid durante dos meses, cruzaron la frontera y se establecieron en París ${ }^{103}$. En París, el jefe revolucionario procuraba, abusando de sus contactos políticos, encontrarles una ocupación. Según López Lapuya: Los emigrados que tenían alguna profesión manual encontraban [...] un modo de ganarse la vida. Pero los sin oficio, los desgraciados militares que habian becho de esta profesión su base de existencia, se encontraban perdidos ${ }^{104}$. Fue el caso de los sargentos fugados, que sobrevivían gracias a los subsidios del partido y a la caridad de sus compañeros.

Así, el alférez Sanz encontró trabajo por mediación de Nicolás Estévanez en un periódico americano, del que fue despedido al poco tiempo. Terminó internado en un hospital psiquiátrico donde murió en 1890. El capitán Casero obtuvo un empleo, por mediación de Ruiz Zorrilla, en la orquesta que actuaba en el Teatro Olympia. Soler, cubano, pudo apoyarse en la numerosa colonia de su procedencia que encontró en París. Otro

101 GARCÍA LADEVESE, Ernesto: op. cit. p. 255.

102 PRIETO Y VILLARREAL, Emilio: op. cit. pp. 257-258.

${ }^{103}$ Ibidem. 323-325.

${ }^{104}$ LÓPEZ LAPUYA, Isidoro: op. cit. p. 117. 
oficial se empeñó en ser cochero a pesar de desconocer el idioma y la ciudad ${ }^{105}$. Prieto trabajó en los almacenes del Louvre, traduciendo al francés los encargos que llegaban desde España. Su trayectoria periodística y literaria le valió un empleo, igualmente precario, en la editorial Garnier ${ }^{106}$. Muchos de ellos (Casero, Prieto, etc.) compaginaron su trabajo con la oficina revolucionaria que Zorrilla. La casa del jefe progresista se convirtió no sólo en el centro neurálgico de la revolución, sino también de la propia emigración ${ }^{107}$.

Tras el fracaso de Villacampa y ante la amenaza inminente de ruptura en el Partido Republicano Progresista, Zorrilla trató de poner fin a su actividad conspirativa y, con ella, a la emigración que de él dependía. Entre diciembre de 1886 y enero de 1887 entabló contactos con el gobierno liberal. Germán Gamazo fue el encargado de negociar con los representantes del jefe revolucionario. La propuesta de Zorrilla era tajante:

Todo lo que yo exijo está reducido a que se conceda amplia y general amnistía a todos los que sufren en el extranjero, en Ultramar o en los presidios por haberse levantado en armas contra la monarquía o la Regencia o ayudado a los que lo hicieron.

Con esto y con dar la pensión que les corresponda a las viudas de los que fallecieron o fueron fusilados o algo equivalente a los que no tengan opción a derechos pasivos quedan satisfechos después de doce años de amarguras y de incesante lucha todos mis deseos ${ }^{108}$.

Los interlocutores alcanzaron un principio de acuerdo. Pero su conclusión no fue posible por la oposición de Moret, que no creía acorde con la dignidad de un gobierno entrar en tratos con un revolucionario ${ }^{109}$. Zorrilla continuó duras penas la lucha revolucionaria durante los nueve años siguientes. La emigración, sin embargo, llegó a su fin en 1891, cuando el gabinete de Cánovas promulgó una amnistía que comprendía delitos de imprenta, rebelión y sedición ${ }^{110}$. Durante la preparación de la Ley se encargó al personal consular un informe sobre los emigrados por causas políticas residentes en cada población de Francia. En las listas que se les remitieron se comprueba la drástica reducción en el número de emigrados republicanos, como efecto de los indultos particulares de 1885 y 1886.

\footnotetext{
105 PRIETO Y VILLARREAL, Emilio: op. cit. pp. 273-275.

106 Ibidem. p. 276-283. LÓPEZ LAPUYA, Isidoro: op. cit. p. 329.

107 Vid. MARTÍNEZ LÓPEZ, Fernando: op. cit.

108 Ruiz Zorrilla a Antonio M. Regidor, (París, 30-12-1886). El desarrollo de las negociaciones puede seguirse en Antonio M. Regidor a Manuel Ruiz Zorrilla, (29-1-1887); Salvador López Tarragoyas a Germán Gamazo, (28-12-1886) y Gamazo a López Tarragoyas, (s/f, enero de 1887); todas ellas en AHFE/AMRZ, VARV 1, Bloque 4.

109 GONZÁLEZ CALLEJA, Eduardo: La razón de la fuerza. op. cit., p. 138. Vid. Embajador de Francia en Madrid al Ministro de Asuntos Exteriores de Francia, (Madrid, 23-2-1887), ADFP, Vol . 911.

${ }^{110}$ Ley de 20-7-1891, en Gaceta de Madrid, no 204, 23-7-1891, p. 279.
} 
En 1891 todavía había en Rennes seis militares procedentes de la sublevación en Badajoz, entre ellos Serafín Asensio Vega y Miguel Caparrós. En Toulouse residían otros tres quienes en su mayoría no se ocupan de otra cosa, sino de sus asuntos mercantiles a los que se encuentran dedicados de algún tiempo a esta parte. Uno de ellos era el coronel Foncuberta, antiguo jefe de la sublevación de la Seo de Urgell. Tres más residían en las proximidades de esta ciudad. En Narbona aparecían cinco. En Cette quedaban otros cinco emigrados políticos, cuatro de ellos militares. El cónsul los clasificaba de la clase jornalera ${ }^{111}$.

La mayor parte de los emigrados consultaron con Zorrilla la actitud a adoptar. Al fin y al cabo, aceptar la amnistía significaba hacer explícita la derrota. De una manera indirecta, el jefe revolucionario les aconsejó aceptarla ${ }^{112}$. En la prefectura de París, Emilio Prieto fue el primero en hacerlo. Le siguieron ocho compañeros de la sublevación de 1886 y otros cuatro del movimiento de 1883. Carlos Casero, pese a que solicitó su inclusión el 14 de noviembre, decidió permanecer en París hasta el regreso de Ruiz Zorrilla a España en $1895^{113}$.

\section{A MODO DE CONCLUSIÓN: SER EMIGRADO DESPUÉS DE LA EMIGRACIÓN}

Volver de la emigración no implicaba necesariamente la mejora de las condiciones de vida. De hecho, ni siquiera suponía la pérdida de la condición de emigrado. La Ley de amnistía de 1891 no contemplaba la reincorporación de los rebeldes al ejército. Les reconocía, eso sí, el retiro con arreglo a los años de servicio que contasen al ser baja en las filas ${ }^{114}$. Sin embargo, la mayoría de los oficiales, como recordaba Prieto y Villarreal, no acumulaban los años suficientes para ello, de modo que sólo les concedió aquella ley el derecho de perecer en España o en el extranjero $^{115}$.

En estas circunstancias, las redes del partido fueron de nuevo fundamentales para facilitar la supervivencia de los antiguos refugiados. Emilio Prieto fundó el periódico El Ideal con el dinero que Ruiz Zorrilla le proporcionó ${ }^{116}$. Carlos Casero regresó a España para

\footnotetext{
111 Vid. Consulado de España en Saint-Nazaire a embajador de España en París, (20-3-1891); Consulado de España en Toulouse a embajador de España en París, (15-3-1891); Consulado de España en Perpiñán a embajador de España en París, (13-3-1891); Consulado de España en Cette a embajador de España en París, (Cette, 4-4-1891) en AGA, 54/5823, Leg. 529.

112 CASERO, Carlos: op. cit. pp. 132-133.

113 Cónsul de España en París al Ministro de Estado, "Relación de los emigrados españoles que se han acogido a la Amnistía de 20 de Julio 1891, en el Distrito de París”, (París, 21-11-1891).

${ }^{114}$ Real Decreto de 22-7-1891, op. cit.

115 PRIETO Y VILLARREAL, Emilio: op. cit. p. 448.

116 Adolfo Menacho al conde de Morphi (s/f, 1893), AGP, Cajón 18, Exp. 15.
} 
colaborar con El Pais ${ }^{117}$. Sesenta y tres emigrados encontraron trabajo en la Exposición Universal de Barcelona gracias a las gestiones del abogado progresista Juan Sol y Ortega ${ }^{118}$. Otros muchos recibieron ayuda del representante de Zorrilla en España, José María Esquerdo ${ }^{119}$.

Haber penado en la emigración o en el presidio conllevaba la adquisición de la categoría de mártir o héroe de la República. Su sacrificio adquirió un valor simbólico que algunos de ellos, como Asensio Vega, Prieto y Villarreal o Carlos Casero, trataron de rentabilizar iniciando, con poco éxito, su carrera política en las filas progresistas. Los tres figuraban en las listas de la coalición republicana en las elecciones a Cortes de $1891^{120}$. En 1893 volvieron a aparecer candidaturas de Casero y Asensio Vega, por Ayamonte y Zaragoza, respectivamente ${ }^{121}$. Prieto no logró ni aún ser concejal en Madrid ${ }^{122}$.

En el seno del partido, sin embargo, su peso simbólico fue explotado con éxito. En la Asamblea de 1895, en la que estalló la ruptura entre defensores del método revolucionario único y partidarios de la vía legal, la voz de los emigrados tuvo más peso que nunca. Carlos Casero, Asensio Vega, Vidaurreta y Jerónimo Pou figuraban entre los primeros. Prieto y Villarreal entre los segundos ${ }^{123}$. Para casi todos ellos, renunciar o relegar a un segundo plano a la revolución tal como la comprendían (es decir, tal como la habían intentado realizar) significaba admitir la inutilidad absoluta de su esfuerzo. Por eso Jerónimo Pou, refugiado desde la sublevación de 1883, se lamentaba de haber pasado algunos años en la emigración, baber sacrificado militando en un partido los mejores años de la vida, carrera, porvenir, familia para que luego [...] le echen a uno porque no se dobla ${ }^{124}$.

\footnotetext{
117 Carlos Casero a Ruiz Zorrilla (7-5-1895), AHFE/AMRZ, Exilio 37, C 47.

118 TATO Y AMAT, Miguel: Sol y Ortega y la politica contemporánea, Madrid, Imprenta Artística Española, 1914, p. 138.

${ }^{119}$ LERROUX, Alejandro: Mis memorias, Madrid, Afrodisio Aguado, 1963, p. 516.

120 Ibídem. p. 423 y El País, (27-1-1891).

${ }^{121}$ El País, (26-2-1893).

122 LÓPEZ LAPUYA, Isidoro: op. cit. pp. 337-338.

${ }^{123}$ El País, (25-3-1895).

${ }^{124}$ Jerónimo Pou a José Artola, (9-5-1895), AHFE/AMRZ, Exilio 37, C 47.
} 